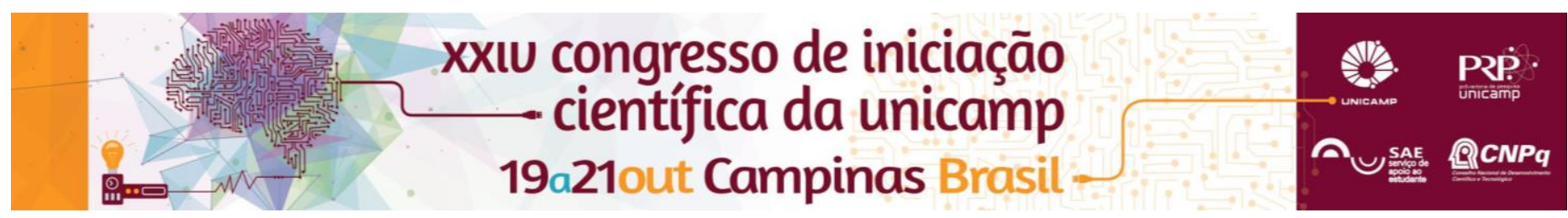

\title{
Melhoria de leiaute de visualizações de grafos de currículos e históricos escolares do software CourseViewer
}

\section{Lucas de Sousa Angelo}

\section{Resumo}

Este projeto consiste em minimizar fatores que prejudicam o entendimento do usuário em relação aos grafos de currículos e históricos escolares do software CourseViewer. Para tanto, tem-se como objetivos específicos a revisão da implementação do algoritmo utilizado pela ferramenta para redução de cruzamentos de arestas e a implementação de algoritmo de ajustes no posicionamento horizontal de vértices em cada camada.

\section{Palavras-chave:}

CourseViewer, visualizações, grafos.

\section{Introdução}

O sistema CourseViewer ${ }^{1}$ utiliza grafos interativos para apresentar disciplinas de um curso, sendo cada nó uma disciplina, cada aresta uma relação de pré-requisito e cada camada do grafo um semestre do curso selecionado. Este projeto teve por objetivos: (1) revisar a implementação das técnicas de heurística baricêntrica e Layer-by-Layer Sweep adotadas ${ }^{2,3}$; e (2) implementar a última fase do framework de Sugiyama et al. ${ }^{3}$ referente ao posicionamento horizontal de vértices, que visa diminuir as curvaturas internas de cada aresta, sem desrespeitar a ordem definida entre os vértices pelo algoritmo de minimização de cruzamentos.

\section{Resultados e Discussão}

Após estudar as técnicas de heurística baricêntrica e Layer-by-Layer Sweep, verificou-se que a implementação atual do algoritmo de descruzamento de arestas no CourseViewer não estava efetivando todos os passos definidos por essas técnicas. Portanto, ele foi recodificado para melhor atender à função de diminuição nos cruzamentos. Após este processo houve uma grande diminuição nos descruzamentos e os resultados obtidos foram positivos (vide Tabela 1). Porém não se conseguiu implementar um dos passos do algoritmo devido à estrutura atual do software.

Tabela 1. Quantidade de cruzamentos, antes e depois da correção do algoritmo, para os grafos de alguns cursos da Unicamp.

\begin{tabular}{|c|c|c|c|}
\cline { 3 - 4 } \multicolumn{2}{c|}{} & \multicolumn{2}{c|}{ Cruzamentos } \\
\hline Catálogo & Curso & Antes & Depois \\
\hline 2012 & 36 & 13 & 9 \\
2012 & 60 & 12 & 9 \\
2012 & 74 & 0 & $\mathbf{0}$ \\
2012 & 83 & 4 & $\mathbf{4}$ \\
2012 & 84 & 22 & 15 \\
2012 & 85 & 53 & 38 \\
2012 & 86 & 53 & 38 \\
2012 & 87 & 28 & $\mathbf{2 8}$ \\
\hline
\end{tabular}

Referente ao posicionamento horizontal foi escolhida a alternativa do algoritmo que compara o posicionamento dos nós com os seus superiores para encontrar a melhor posição possível, sem fugir à ordem predefinida de nós dentro de cada camada 4 . Desta forma foi possível obter melhorias no grafo, podendo notar a diminuição da curvatura das arestas, deixando-as em posição mais próxima da vertical.
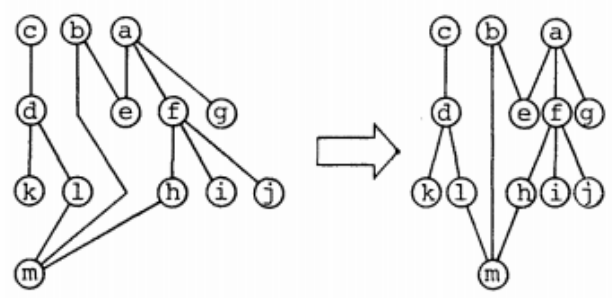

Figura 1. Exemplo de aplicação da reorganização horizontal (esquerda: antes; direita: depois).

\section{Conclusões}

A visualização do grafo foi melhorada, pois houve uma diminuição considerável no cruzamento de arestas e com o algoritmo de posicionamento horizontal houve também diminuição nas curvas. Seguindo os critérios definidos por Sugiyama et al. ${ }^{3}$, é possível mensurar o quão bom está o desenho de um grafo; estes critérios são, em ordem de prioridade: número de curvas nas arestas, número no cruzamento de arestas, ângulo mínimo entre arestas, desenho ortogonal em grade e simetria do desenho. Podemos afirmar desta forma que as melhorias foram efetuadas nos tópicos mais prioritários e importantes da visualização do grafo, cumprindo assim o objetivo deste projeto.

\section{Agradecimentos}

Agradecimentos à PRP e ao $\mathrm{CNPq}$ pelo financiamento deste projeto.

${ }^{1}$ Oliveira, M. R. ; Mendonça, P. J. C. ; Leardine, A. F. G. ; Gonçalves, V. P. Medina, B. F. ; Silva, C. G. (2013). CourseViewer - a prototype for visualizing undergraduate courses and student transcripts. Proceedings of SIBGRAPI 2013

2 Bastert, O.; Matuszewski, C. (2001). "Layered drawings of digraphs". In Kaufmann, M.; Wagner, D. (eds.), Drawing Graphs: Methods and Models, LNCS 202, pp.104-139. Springer, 2001

3 Sugiyama, K.; Tagawa, S.; Toda, M. (1981). "Methods for visual understanding of hierarchical system structures". IEEE Transactions on Systems, Man and Cybernetics 11(2), pp. 109-125.

4 Brandes, U., Köpf, B. (2001). "Fast and Simple Horizontal Coordinate Assignment". Proceedings of the $9^{\text {th }}$ International Shmposium on Graph Drawing, p.31-44, September 23-26, 2001 